\title{
"Se tem batimento, tem vida": vivências em torno da hospitalização na visão de familiares de pacientes internados no CTI
}

\author{
"If you have beat, have life": living about hospitalization in the vision of familiars of patients \\ inside in the ICU
}

"Si tiene latido, tiene vida": vivencias en torno de la hospitalización en la visión de familiares de pacientes internados en el CTI

Ewerton Beckman dos Reis ${ }^{1 *}$, João Eduardo Barros Branco ${ }^{1}$, Chiara Silmara Santos Silva ${ }^{1}$, Rafael Santana Costa Torres ${ }^{1}$, João Otávio Pinheiro Borges ${ }^{1}$, Alice Dayenne Moraes ${ }^{2}$, Jessica Soares Barbosa $^{1}$, Esleane Vilela Vasconcelos ${ }^{1}$.

\section{RESUMO}

Objetivo: relatar as vivências de familiares como acompanhante de um paciente internado no Centro de Terapia Intensiva e analisar suas implicações para a enfermagem. Métodos: trabalho tipo descritivo, com abordagem qualitativa. Coleta de dados feita por entrevista utilizando roteiro semiestruturado contendo perguntas abertas e questionário socioeconômico. Amostra composta por 20 familiares de pacientes internados no CTI do Hospital Universitário João de Barros Barreto, em Belém-Pará. Foi escolhida a análise de conteúdo temática para elaboração das unidades. Resultados: o perfil da maioria dos familiares da pesquisa foi de mulheres, solteiras, católicas, entre a faixa etária de 20-30 anos com ensino médio completo e pertencentes majoritariamente ao grau de parentesco natural. Analisamos os resultados com base na repetição de termos e significados nas falas dos familiares. Dos significados surgiram duas categorias para o estudo: Compreensão do CTI e repercussões emocionais para os familiares e $\mathrm{O}$ núcleo familiar durante a hospitalização. Conclusão: entender os anseios do acompanhante de forma singular e como componente de família é estabelecer atitude profissional visando à integralidade do serviço.

Palavras-chave: Enfermagem, Centro de Terapia Intensiva, Família.

\begin{abstract}
Objective: to report the experiences of family members as companion of an inpatient in the Intensive Care Unit and to analyze its implications for nursing. Methods: descriptive work, with a qualitative approach. Data collection by interview using semi-structured script containing open questions and socioeconomic questionnaire. Sample composed of 20 relatives of patients admitted to the ICU of the João de Barros Barreto University Hospital, in Belém-Pará. Thematic content analysis was chosen for the elaboration of the units. Results: the profile of the majority of the family members of the study was female, single, catholic, between the age group of 20-30 years old with full secondary education and belonging mainly to the degree of natural kinship. We analyzed the results based on the repetition of terms and meanings in the speeches of the relatives. From the meanings came two categories for the study: Understanding ICU and emotional repercussions for family members and the family nucleus during hospitalization. Conclusion: understanding the wishes of the companion in a singular way and as a family component is to establish a professional attitude aiming at the integrality of the service.
\end{abstract}

Key words: Nursing, Intensive Care Unit, Family.

1 Universidade Federal do Pará (UFPA), Belém-Pará. *E-mail: ewerbck@gmail.com

2 Universidade do Estado do Pará (UEPA), Belém-Pará. 


\section{RESUMEN}

Objetivo: relatar las vivencias de familiares como acompañante de un paciente internado en el Centro de Terapia Intensiva y analizar sus implicaciones para la enfermería. Métodos: trabajo tipo descriptivo, con abordaje cualitativo. Recolección de datos realizada por entrevista utilizando itinerario semiestructurado que contiene preguntas abiertas y cuestionario socioeconómico. La muestra consta de 20 familiares de pacientes internados en el CTI del Hospital Universitario João de Barros Barreto, en Belém-Pará. Se eligió el análisis de contenido temático para la elaboración de las unidades. Resultados: el perfil de la mayoría de los familiares de la investigación fue de mujeres, solteras, católicas, entre el grupo de edad de 20-30 años con educación media completa y pertenecientes mayoritariamente al grado de parentesco natural. Se analizan los resultados en base a la repetición de términos y significados en las conversaciones de los familiares. Dos significados emergerán dos categorías para o estudio: Comprensión de CTI y repercusiones emocionales para parientes y El núcleo familiar durante una hospitalización. Conclusión: entender los anhelos del acompañante de forma singular y como componente de familia es establecer una actitud profesional para la integralidad del servicio.

Palabras clave: Enfermería, Centro de Terapia Intensiva, Familia.

\section{INTRODUÇÃO}

A nível sociocultural perdura-se o mito de que os pacientes internados ou, que irão para a terapia intensiva, dificilmente sairão com vida. Afinal, emaranhado a esta ideia, estão reforços negativos, como o medo da morte, da perda da autonomia, em suma, fatores agravantes ao quadro clínico do paciente e seu prognóstico (BETTINELLI LA e ERDMANN AL, 2009).

Ao direcionar o foco para os familiares, amigos e todos que fazem parte do círculo social do paciente internado, pode-se perceber um leque de alterações intrínsecas e extrínsecas que estes passarão: a "montanha russa" emocional, preocupações, ansiedade, estresse; mudança de rotina, despesa econômica, adoecimento, etc., são alguns exemplos dessa "via crucis" (OTHERO M e CARLO MMRP, 2006).

De acordo com Beuter $\mathrm{M}$ et al (2012), é preciso entender o familiar como elemento importante na melhora do paciente. A enfermagem precisa criar estratégias para entender as demandas do acompanhante que modificará sua rotina de trabalho, de sono, de alimentação e de humor para tentar se adequar às normas e rotinas do Centro de Terapia Intensiva (CTI). Esse aumento exponencial de emoções pode refletir na dificuldade em adaptar-se ao ambiente hospitalar e manter um contato harmonioso com a equipe multiprofissional.

A enfermagem tem como ferramenta a comunicação, esta quando realizada de forma empática, respeitosa e acessível facilita o processo de vínculo entre a equipe e os familiares. Como afirma dos Santos ES et al (2016), essa ponte entre o serviço e o acompanhante se dá pela prática educativa e tem como objetivo trazer informação sobre o ambiente do CTI. Essa atividade exercida de pela enfermagem almeja mostrar o CTI de forma mais tranquila, dialogando entre o que os familiares sabem sobre o CTI e a realidade do serviço.

A pesquisa em questão surgiu por meio do contato com os familiares de pacientes internados durante 0 horário de visitas, no projeto de extensão intitulado "O Cotidiano de Familiares de Pacientes Internados no CTI". Esse momento promoveu espaço de diálogo entre acadêmicos e familiares sobre a rotina do CTI, o aparato tecnológico além de fornecer apoio emocional. No decorrer das conversas, sempre foi identificado um desconhecimento e estigmatização do CTI. A representação como um local de morte alterava as emoções já presentes naquele familiar sensibilizado pela dor de ter um ente querido em situação, em alguns momentos, terminal.

O estudo justifica-se pela necessidade de estender a atenção para o familiar e relatar os impactos advindos da hospitalização em um local de cuidados intensivos. A internação hospitalar altera a rotina e o estado psicológico do acompanhante pelo constante medo da morte e perda daquele ente querido. A partir do exposto, o estudo tem como objetivo relatar as vivências de familiares como acompanhante de um paciente internado no Centro de Terapia Intensiva e analisar suas implicações para a enfermagem. 


\section{MÉTODOS}

O trabalho realizado é do tipo descritivo, com abordagem qualitativa. A pesquisa foi realizada no Centro de Terapia Intensiva do hospital Universitário João de Barros Barreto (HUJBB). Participaram deste estudo vinte (20) familiares de pacientes internados no Centro de Terapia Intensiva que expressaram o desejo de participar desta pesquisa. Para garantir o vínculo de confiança entre o entrevistador e os sujeitos do estudo, a coleta de dados foi realizada posterior à atividade realizada pelo extensionista do projeto "O cotidiano de familiares de pacientes internados no CTI" a fim de haver o entendimento da importância da atividade e da pesquisa.

Para inclusão na pesquisa, o critério estabelecido foi de ser familiar maior de 18 anos com permanência mínima de duas (2) visitas após a hospitalização do seu familiar e assinatura do Termo de Consentimento Livre e Esclarecido (TCLE). E para exclusão foi estabelecido familiar com menos de duas (2) visitas e que não assinar o TCLE.

A coleta de dados foi realizada durante o horário de visitas no turno da tarde, entre os meses de maio a julho de 2018. A coleta de dados foi feita por entrevista utilizando um roteiro semiestruturado contendo perguntas abertas e um questionário socioeconômico. No questionário socioeconômico as seguintes variáveis foram questionadas: sexo, idade, grau de parentesco, religião, estado civil e escolaridade. Na segunda parte, com perguntas abertas, questionou-se: 1 - O que você sente antes de entrar no CTI? ; 2- Como você se sente vendo seu familiar no leito do CTI? ; 3- Quais consequências trouxeram para sua vida ter um familiar seu no CTI? ; 4- Você percebe que há um interesse pela equipe de saúde em melhorar o estado de saúde do seu familiar? Como? ; e 5- Você se sente satisfeito com o serviço prestado? Por quê?

Os acompanhantes foram delimitados por códigos alfanuméricos para delimitação das falas e para preservação do seu anonimato, por exemplo F1, F2, F3 e etc.

A análise de conteúdo foi definida como a técnica para análise de comunicações. A análise de conteúdo busca inferir sobre os dados característicos das variáveis inferidas e os fatores determinantes para essas características (BARDIN L, 2016).

Esta pesquisa foi aprovada pelo comitê de ética em pesquisa em seres humanos do hospital universitário João de Barros Barreto com protocolo de número 1.988.935, CAAE: 61422116.9.3001.0017. Sendo respeitados os princípios estabelecidos em pesquisas realizadas com seres humanos, de acordo com a Resolução 466/12.

\section{RESULTADOS e DISCUSSÃO}

A Tabela 1 apresenta o perfil sócio demográfico dos participantes. Com relação ao sexo, houve predomínio do feminino na amostra de $20(100 \%)$ participantes durante as visitas. Há um aspecto cultural atribuído a mulher como sinônimo de cuidado, resultando em uma maior participação no serviço de saúde.

Resultado semelhante ocorreu no estudo de Nascimento VF (2013), afirmando a visita da mulher como mais intensa mesmo na presença de pais hospitalizados. Aos homens o cuidado só era mais necessário quando vinculados a atividades instrumentais da vida diária.

Com relação ao grau de parentesco, A formação de três grupos com mesmo quantitativo de participantes é um achado interessante, pois mostra o envolvimento da família como um todo no processo de hospitalização, essa alta frequência é causa da grande afinidade entre o familiar e o paciente. Vale ressaltar os achados de Nunes MEP e Gabarra LM (2018), demonstrado que $80 \%$ dos acompanhantes da pesquisa eram cônjuges dos pacientes internados, resultado contrário a presente pesquisa (Tabela 1).

Já quanto à idade, houve predomínio de adultos entre 20 e 40 anos (60\%). O presente estudo obteve resultado contrário ao estudo de Nascimento VF (2013), no estudo, o predomínio da faixa etária foi de $43 \%$ para adultos com 41 a 50 anos, afirmando ser um achado comum com pesquisas sobre acompanhantes (Tabela 1). 
Tabela 1 - Caracterização sócio demográfica dos participantes da pesquisa, N=20, Belém, PA, Brasil, 2018.

\begin{tabular}{|c|c|c|}
\hline Variável & $\mathbf{N}$ & $\%$ \\
\hline \multicolumn{3}{|l|}{ Sexo } \\
\hline Masculino & 8 & 40 \\
\hline Feminino & 12 & 60 \\
\hline \multicolumn{3}{|l|}{ Idade } \\
\hline $20-30$ & 5 & 25 \\
\hline $31-40$ & 7 & 35 \\
\hline $41-50$ & 4 & 20 \\
\hline $51-60$ & 4 & 20 \\
\hline \multicolumn{3}{|l|}{ Grau de parentesco } \\
\hline Filha/Filho & 5 & 25 \\
\hline Irmã/Irmão & 5 & 25 \\
\hline Mãe/Pai & 5 & 25 \\
\hline Tia/Tio & 4 & 20 \\
\hline Avó & 1 & 5 \\
\hline \multicolumn{3}{|l|}{ Escolaridade } \\
\hline Ensino Fundamental & 1 & 5 \\
\hline Ensino Fundamental incompleto & 2 & 10 \\
\hline Ensino Médio & 10 & 50 \\
\hline Ensino Médio incompleto & 1 & 5 \\
\hline Ensino Médio Técnico & 1 & 5 \\
\hline Ensino Superior & 5 & 25 \\
\hline \multicolumn{3}{|l|}{ Estado civil } \\
\hline Solteiro & 11 & 55 \\
\hline Casados & 5 & 25 \\
\hline Divorciados & 2 & 10 \\
\hline União estável & 2 & 10 \\
\hline \multicolumn{3}{|l|}{ Religião } \\
\hline Católicos & 11 & 55 \\
\hline Evangélicos & 6 & 30 \\
\hline Cristãos & 2 & 10 \\
\hline Espirituoso & 1 & 5 \\
\hline
\end{tabular}

Fonte: dos Reis EB, et al. 2018.

No aspecto escolar, mais da metade da população do estudo apresenta o nível médio completo (adicionado os participantes com nível superior e o participante com nível médio técnico). Esse fato permitiu melhor articulação durante as conversas e melhor entendimento sobra à proposta da pesquisa por parte dos familiares (Tabela 1).

Já quanto à religião, resultado semelhante surgiu na pesquisa de Matias LC e Resende MC (2018), onde as autoras encontraram na sua amostra $50 \%$ de católicos. Na pesquisa, as autoras ressaltam a importância da religiosidade como instrumento diminuidor de ansiedade durante a hospitalização (Tabela 1).

Dessa forma o perfil da maioria dos familiares que participou da pesquisa foram mulheres, solteiras, católicas, entre a faixa etária de 20 a 40 anos com ensino médio completo e pertencentes majoritariamente ao grau de parentesco natural (Pais, irmãos e filhos).

Posteriormente ao término da coleta de dados, analisamos os resultados com base na repetição de termos e significados nas falas dos familiares. Após as devidas demarcações, esses significados foram delimitados em categorias, posteriormente definidos em unidades. Dessa forma, dos significados surgiram duas categorias para o estudo: I- Compreensão do CTI e repercussões emocionais para os familiares e II- O núcleo familiar durante a hospitalização. 


\section{I- Compreensão do CTI e repercussões emocionais para os familiares}

Essa categoria aborda sobre a imagem do Centro de Terapia Intensiva (CTI) na concepção dos familiares bem como o impacto emocional vivenciado pelos familiares. É importante destacar o aparecimento de CTI e Unidade de Terapia Intensiva (UTI) nas falas dos acompanhantes, pois para a grande maioria os termos eram semelhantes.

Já iniciado desde o momento da indicação ao leito do CTI, dentro dessa perspectiva, o núcleo familiar sofre importante ruptura com relação ao seu ente hospitalizado. De acordo com dos Santos ES et al (2016), o conhecimento dos familiares em torno do CTI é ínfimo em relação à estrutura, ações e sua rotina. Além disso, a imagem vinculada a esse ambiente é do local final de vida, onde há um alerta máximo com relação à integridade do familiar, evidenciado nos seguintes relatos:

"No primeiro momento foi aquele choque, um impacto muito forte, em relação com a parte de UTI, ta relacionado a morte e aquela coisa tem na cabeça da gente." (F13)

"Primeira coisa que eu pensei em CTI/UTI foi „pronto ", que perdi minha irmã assim né, ela foi pra cti, "será que eu vou ter a mesma lembrança da minha irmã?" (F14)

Os discursos dos familiares corroboram com o estudo de Leite MT et al (2015), no qual evidencia a percepção de um CTI com imagem negativa atrelada a quantidade de procedimentos e a iminente morte do ente querido. Essa visão pode ser agravada com relação à faixa etária, falta de informação e motivo de internação do paciente além de experiências anteriores.

Como exposto por Cosmo Monteiro $\mathrm{M}$ et al (2016), essa imagem criada em torno do CTI é multifatorial (aumento da incidência de doenças crônicas e degenerativas bem como o envelhecimento populacional), contudo afirma também que a escolha para admissão tem influenciado nessa imagem. O CTI deve atender pacientes com possibilidade de reverter o seu quadro atual de saúde com foco na cura, entretanto escolhas ruins para internação têm dado margem para pacientes em estados terminais entrarem no $\mathrm{CTI}$. O senso comum negativo ao CTI pode ser evidenciado ainda pelas seguintes falas:

"Para te falar a verdade mano, eu sinto um arrepio antes de entrar né, não to acostumado em ver essas coisas assim." (F2)

"Vamos preparar ele que ele vai para UTI. quando ela falou isso, fiquei com as minhas pernas tremendo, né, porque nunca passei por uma situação dessa." (F9)

A imprevisibilidade encontrada nas falas é demonstrada no estudo de Reis LCC et al (2016), evidenciando essa imprevisibilidade como decorrente da incerteza com relação à cura do paciente e a falta de paciência com relação à espera de informações. Nesse momento é importante a postura do profissional no repasse de informações, pois como afirmado pelo estudo do autor, a dor que o familiar sente durante a hospitalização torna o recebimento de informações mais demorado. Requisitando assim mais paciência do profissional em repassar informação.

O esclarecimento permite a mudança do estigma presente no CTI. A assistência de enfermagem deve englobar a família para gradativamente permitir o entendimento sobre a hospitalização, bem como as ações impostas pela rotina de serviço. É importante destacar na pesquisa o aparecimento de falas com concepção positiva com relação ao $\mathrm{CTI}$, evidenciando a compreensão de alguns acompanhantes sobre a necessidade de internação no CTI como ambiente de esperança para melhora de saúde de seus familiares:

"ao mesmo tempo confortável por ele estar no lugar certo." (F7)

"CTI não é bom, né?! mas ele ta ali pro bem dele, porque se ele não estiver ali, podia acontecer coisa pior." (F8)

$\mathrm{O}$ acolhimento deve ser adotado como postura entre os profissionais, contribuindo com conhecimento válido para o acompanhante. Neste momento, escuta e resolução devem ser abraçados para desmitificar 0 senso comum preexistente no CTI (PASSOS SSS et al, 2015). Essa abordagem leva em consideração a existência de uma família aguardando informação sobre o ente hospitalizado, e esse acompanhante tem a possibilidade de diminuir as repercussões negativas da vivência em um hospital para esse núcleo familiar. 
Juntamente a imagem criada em torno do CTI, os familiares apresentaram as repercussões emocionais desencadeadas por ter um parente internado. Houve uma ambivalência de emoções, positivas e negativas. Contudo é importante ressaltar que $12(60 \%)$ dos acompanhantes manifestaram sentimentos negativos, traduzidos por ansiedade, nervosismo e apreensão. Destacam se as seguintes falas:

"Assim, de mim mesmo eu me sinto um pouco apreensiva sabe de chegar lá no, ai meu deus, de ver ele naquela situação que ele ta." (F16)

"quando eu chego aqui eu fico logo ansiosa né, porque eu quero entrar logo pra ver minha mãe, como ela ta." (F15)

Como observado nas falas, há uma angústia no momento de visitação para ver o quanto antes o parente hospitalizado. Grande parte desses sentimentos está atrelada a imagem do CTI previamente estabelecida no texto, como local de morte e sofrimento. O estudo de dos Santos ES et al (2016), acrescentou ainda sobre a questão da falta de privacidade e exposição no CTI como um agravante para os sentimentos dos familiares. Essa ansiedade acaba dando margem para um indivíduo mais enfraquecido psicologicamente, predisposto a conflitos com o serviço e em sua rede familiar. De acordo com a autora, a enfermagem é a profissão capaz de minimizar esses sentimentos por estão em maior parte junto ao indivíduo.

O achado nas falas teve resultado oposto ao estudo de Nascimento VF et al (2015), o autor expôs em seu estudo sobre sentimento de alívio por parte dos familiares por seus pacientes estarem em uma unidade de cuidados intensivos (73,3\%). O entendimento sobre a hospitalização (rotina e aparelhos) demonstrou ser um fator crucial para acalmar os ânimos dos familiares. $O$ autor ainda afirma que esse percentual trouxe como consequência o sentimento de recuperação concreta de saúde do paciente acamado por parte dos familiares.

Dessa forma, ficou evidente nesta unidade a imagem de morte presente no CTI como senso comum de acompanhantes. O motivo de internação e prévia informação sobre o local ainda são pontuais para nortear a forma como esse familiar irá aceitar a hospitalização. A participação da enfermagem nesse processo é de extrema importância para promover um espaço acolhedor para o familiar se sentir confortável em expor suas angústias e dúvidas e dessa forma, repercutir no cuidado prestado a esse familiar também.

\section{II- O núcleo familiar durante a hospitalização}

A internação ultrapassa aspectos intra-hospitalares refletindo no cotidiano do acompanhante e sua família. Emoções, aspectos físicos e relações sociais são modificados e até ampliadas durante esse período. Durante esse processo de espera de alta, alguns familiares "aproveitam" para refletir sobre o quadro de saúde de seu ente hospitalizado e tentam internalizar a experiência para sua vida. Alguns familiares pontuaram a hospitalização como momento de reflexão sobre postura e modo de vida. Como encontrado nas falas abaixo:

"eu vivo me culpando será que eu trouxe a mamãe, fiz coisa errada, passa pela minha cabeça sabe, de ter feito alguma coisa antes." (F15)

"[...] A outra consequência é positiva, porque eu chamo os meus irmão e irmãs que fumam cigarro e bebem e digo: Nós estamos com irmão lá, acamado, rebentado, a consequência é o uso do cigarro e de álcool e, também de drogas." (F4)

Como visto nas falas, há um esforço em tentar extrair algum aprendizado sobre o momento difícil na qual a família está passando. Essa postura é confirmada no estudo de Reis LCC et al (2016), intitulando uma ressignificação da vida por parte dos familiares de pacientes internados.

Essa ressignificação pode se mostrar de forma positiva como exposto pelo familiar $F 4$, demonstrando os efeitos tóxicos do uso de cigarro e álcool para o seu núcleo familiar através da hospitalização de um membro próximo, bem como pode trazer sentimentos negativos como culpa e arrependimento, encontrado na fala do familiar F15. Entender o familiar como extensão do paciente permite avaliar a repercussão da hospitalização na sua vida e como ele está lidando com ela, mesmo de forma temporária.

É importante destacar que o núcleo familiar apresenta também uma ressignificação coletiva no momento da hospitalização. Como observado nas falas, os familiares na iminência de perder o ente querido optam por 
deixar diferenças de lado e escolhem por atuar de forma sinérgica em prol da efetivação do laço familiar. Como pode ser visto nas seguintes falas:

\author{
"Uniu mais acho que os irmãos." (F6) \\ "é porque minha familia, [...], eles ficaram mais unidos ainda porque eles viram \\ assim pensando que iam perder o pai deles." (F3)
}

Esse é um achado extremamente positivo, pois segundo estudo de Santos DG e Caregnato RCA (2013), essa união entre familiares para participação na recuperação do paciente é conflituosa, demonstrando ser um dos principais geradores de tristeza e conflito no CTI. Um dos motivos levantados no estudo é o grau de conhecimento sobre a situação do paciente. Durante a pesquisa, alguns familiares não se sentiam confortáveis com o estado de saúde do paciente e escolhiam não realizar mais visitas.

Durante as entrevistas, para manter a frequência de visitações e não deixar o paciente sentindo se abandonado, alguns familiares abdicaram de outras atividades para dar atenção total às demandas do hospital. Nas falas ficou evidente o peso que a hospitalização gradativamente iria influenciando em seus meios profissionais e sociais.

"Eu não consigo mais fazer muita coisa na minha vida porque eu fico preocupada com ele porque sou só eu de filha." (F10)

"Fico desanimado assim pra tudo sabe, pra sair essas coisas, ficar mais em casa." $(F 2)$

Chaves OCS et al (2015), complementa em seu estudo sobre essa responsabilidade abraçada pelo familiar. Na concepção do acompanhante, para estar disposto a ajudar na recuperação do paciente, o acompanhante deve sempre colocar as necessidades do outro em primeiro plano. Além disso, afirma sobre a escolha de participar ou não de forma ativa no acompanhamento. Essa escolha leva em consideração a obrigação e o cuidado por amor.

A falta de energia e cansaço progressivos criados pela hospitalização demonstrou interferir diretamente na vida profissional em alguns participantes da pesquisa. A baixa produtividade pode se tornar um risco para a permanência no trabalho ou execução dos serviços. Em um estudo feito em uma UTI pediátrica, Santos LM et al (2014), demonstrou que as mães presentes na pesquisa se tornaram mais propensas a deixar seus empregos para ficar ao lado de seus filhos, devido ao vínculo já estabelecido entre mãe e criança.

A participação do familiar no momento da visita foi delimitada pelo grau de integração com estrutura e rotina. Essa integração é estabelecida de forma satisfatória quando o profissional de enfermagem estabelece escuta e orientação para os familiares antes da visita. Durante a pesquisa, foi notado que eram repassados primeiramente os informes com relação à rotina e materiais para a UTI posteriormente era feito 0 esclarecimento dos aparelhos e evolução clínica do paciente

\title{
CONSIDERAÇÕES FINAIS
}

A enfermagem precisa estabelecer esse momento com o familiar e permitir a construção de vínculo com os usuários do serviço. O cuidado deve perpassar o indivíduo e chegar à família, transformando-a em aliada na busca da melhora do seu paciente hospitalizado. O acolhimento permitiu a mudança gradativa da visão dos familiares sobre o CTI. O projeto de extensão, cenário para formular o presente estudo, permitiu um momento rápido porem simples e direto durante o horário de visitação para conversa com os familiares. Nele a retirada de dúvidas permitiu com que os familiares entendessem de forma simples a necessidade de determinados procedimentos.

\section{REFERÊNCIAS}

1. ARAGÃO J. Introdução aos estudos quantitativos utilizados em pesquisas científicas. Revista Práxis. $2011 ; 59-62$.

2. BARDIN L. Análise de conteúdo / Laurence Bardin; Tradução Luís Antero Reto, Augusto Pinheiro. São Paulo: edições 70, 2016; 128-168. 
3. BEUTER M, et al. Sentimentos dos familiares acompanhantes. Esc Anna Nery (impr.)2012 jan-mar; 16 (1):134-140.

4. BETTINELLI LA, ERDMANN AL. Internação em Unidade de Terapia Intensiva e a família: perspectivas do cuidado. Avances en enfermeira. Vol XXVOO, № 1. Enero-Junio, 2009.

5. BOSI MLM. Pesquisa qualitativa em saúde coletiva: panorama e desafios. Ciência \& Saúde Coletiva, 2012.;17(3):575-586.

6. CHAVES OCS, et al. "Tem que cuidar": vivências e saberes do familiar/cuidador de paciente com doença crônica. Revista de enfermagem UFPE, 2015; 9535-9540.

7. COSMO MONTEIRO M, et al. Terminalidade em UTI: dimensões emocionais e éticas do cuidado do médico intensivista. Psicologia em Estudo, 2016.

8. DOS SANTOS ES, et al. Acolhimento e processo educativo em saúde a familiares de pacientes internados em UTI adulto. Cienc Cuid Saude, 2016; 639-646.

9. GASPAR MRF, et al. A equipe de enfermagem e a comunicação com o paciente traqueostomizado. Rev. CEFAC. 2015 maio-Jun; 17(3):734-744.

10. LEITE MT, et al. A hospitalização em unidade de terapia intensiva na voz de idosos e familiares. Estudos Interdisciplinares sobre o Envelhecimento, 2015.

11. MATIAS LC, RESENDE MC. Ansiedade e religiosidade de familiares de pacientes internados em unidade de terapia intensiva. Perspectivas em Psicologia, 2018; 38-53.

12. NASCIMENTO VF, et al. Percepções de familiares sobre hospitalização no ambiente intensivo. Rev. enferm. UFPI, 2015; 92-99.

13. NASCIMENTO VF. Indivíduos frequentadores de UTI em um município no interior do Brasil. Revista Eletrônica Gestão \& Saúde Vol.04, 2013; 1445-1460.

14. NUNES MEP, GABARRA LM. Vivência de Familiares Sobre Visita de Crianças e Adolescentes em UTI Adulto. Revista Psicologia e Saúde, 2018; 109-125.

15. OLIVEIRA GR, BARBOSA FC. Entre o fim e o recomeço: sentidos atribuídos ao fenômeno vivido na internação em unidade terapia intensiva adulto. Revista Brasileira de Ciências da Vida, 2018.

16. OTHERO M, CARLO MMRP. Família Diante do Adoecimento e da Hospitalização Infantil - Desafios Para a Terapia Ocupacional. Desafios Para a Terapia Ocupacional. Prática Hospitalar. 111-117.

17. PASSOS SSS, et al. O acolhimento no cuidado à família numa unidade de terapia intensiva. Rev enferm UERJ, 2015; 23(3):368-74.

18. REIS LCC, et al. As repercussões do processo de internação em UTI adulto na perspectiva de familiares. Temas em Psicologia, 2016; 815-828.

19. SANTOS DG, CAREGNATO RCA. Familiares de pacientes em coma internados na Unidade de Terapia Intensiva: percepções e comportamentos. Revista Eletrônica de Enfermagem, 2013; 487-95.

20. SANTOS LM, et al. Mudanças familiares decorrentes da hospitalização do prematuro em cuidados intensivos: um estudo com puérperas. Revista Baiana de Enfermagem, 2014.

21. SILVA FMV, et al. Estratégias Utilizadas por Enfermeiros para Minimizar a Assimetria na Comunicação em Unidade de Terapia Intensiva. Rev. Aten. Saúde, 2018; 110-117.

22. SPOHR VM, et al. Sentimentos Despertados Em Familiares De Pessoas Internadas Na Unidade De Terapia Intensiva. Cogitare Enferm. 2013; 18(4):736-42. 